\title{
Long-term effectiveness and safety of secukinumab for treatment of refractory mucosal and articular Behçet's phenotype: a multicentre study
}

\author{
Filippo Fagni, ${ }^{1}$ Alessandra Bettiol, ${ }^{2}$ Rosaria Talarico (D) , ${ }^{3}$ Giuseppe Lopalco (D) , \\ Elena Silvestri, ${ }^{1}$ Maria Letizia Urban, ${ }^{1}$ Paul A J Russo, ${ }^{5}$ Gerardo Di Scala (D) , \\ Giacomo Emmi, ${ }^{1}$ Domenico Prisco ${ }^{1}$
}

\begin{abstract}
Handling editor Josef S Smolen

- Additional material is published online only. To view please visit the journal online (http://dx.doi.org/10.1136/ annrheumdis-2020-217108)
\end{abstract}

'Department of Experimental and Clinical Medicine, University of Florence, Firenze, Italy

${ }^{2}$ Department of Neurosciences, Psychology, Drug Research and Child Health (NEUROFARBA), University of Firenze, Firenze, Italy

${ }^{3}$ Rheumatology Unit, Department of Clinical and Experimental Medicine, University of Pisa, Pisa, Italy ${ }^{4}$ Rheumatology Unit, Department of Emergency and Organ Transplantation, University of Bari, Bari, Italy ${ }^{5}$ Chandlers Hill Surgery, Adelaide, South Australia, Australia

\section{Correspondence to}

Dr Gerardo Di Scala,

Department of Experimental and Clinical Medicine, University of Florence, Firenze 50121, Italy; discalagerardo@gmail.com

$F F$ and $A B$ contributed equally.

GE and DP are joint senior authors.

Received 5 February 2020 Revised 4 April 2020 Accepted 20 April 2020

Check for updates

(C) Author(s) (or their employer(s)) 2020. No commercial re-use. See rights and permissions. Published by BMJ.

\section{To cite: Fagni $F$,}

Bettiol A, Talarico $R$, et al. Ann Rheum Dis Epub ahead of print: [please include Day Month Year]. doi:10.1136/ annrheumdis-2020-217108

\section{ABSTRACT}

Objective To evaluate the effectiveness and safety of secukinumab in patients with a mucosal and articular Behçet's phenotype resistant to conventional and biologic treatment.

Methods A multicentre retrospective study was performed on 15 patients with a mucosal and articular phenotype of Behçet's syndrome fulfilling the International Criteria for Behçet's Disease and refractory to treatment with colchicine, disease-modifying antirheumatic drugs and at least one antitumour necrosis factor- $\alpha$ agent. Minimum follow-up was set at 6 months. Six patients with a polyarticular involvement were treated with secukinumab $300 \mathrm{mg} / \mathrm{month}$, while all other cases received secukinumab $150 \mathrm{mg} /$ month. Dose increase from 150 to $300 \mathrm{mg}$ per month and shortening of administration frequency were allowed for poor disease control. Response evaluation was based on the number of oral ulcers in the previous 28 days and Disease Activity Score-28 for articular manifestations. Results At 3 months of follow-up, nine (66.7\%) patients achieved a response (complete or partial), and this proportion further increased to $86.7 \%$ at 6 months, $76.9 \%$ at 12 months, $90.0 \%$ at 18 months and $100.0 \%$ after 24 months. Notably, all patients who started with secukinumab $300 \mathrm{mg} / \mathrm{month}$ achieved complete response by month 6 . Seven (46.7\%) patients could achieve a response only after switching to a higher dosage. Conclusions Our study suggests that secukinumab at a dose of 150 and $300 \mathrm{mg}$ per month is safe and effective for the long-term treatment of patients with Behçet's syndrome with a mucosal and articular phenotype refractory to previous treatments. Notably, secukinumab $300 \mathrm{mg} / \mathrm{month}$ resulted in superior complete mucosal and articular responses with no serious or dose-related adverse effects.

\section{INTRODUCTION}

Behçet's syndrome (BS) is a systemic vasculitis of unknown aetiology characterised by a heterogeneous clinical picture, with evidence that different disease manifestations cluster to constitute discrete phenotypes, ${ }^{12}$ probably as the result of different pathogenic pathways. ${ }^{3}$

Mucosal lesions, particularly oral and genital ulcers, are the most recognisable feature of BS and one of the most disabling due to their high impact on patients' quality of life. ${ }^{4}$ Despite there not

\section{Key messages}

What is already known about this subject?

- Behçet's syndrome (BS) is a multisystemic vasculitis characterised by discrete clinical phenotypes, presumably as an expression of different pathophysiological mechanisms.

- The anti-interleukin (IL)-17 agent secukinumab showed efficacy in controlling refractory mucosal and axial articular manifestations in a small cohort of patients with BS.

What does this study add?

- Therapy with the anti-IL-17 agent secukinumab is safe and effective in patients with BS with a mucosal and articular phenotype refractory to previous conventional and biologic treatments.

- Positive effects were also observed in other aspects of the disease, such as genital aphthosis, axial arthritis and intestinal manifestations, with no exacerbations of other BS manifestations.

How might this impact on clinical practice or future developments?

- A phenotype-tailored therapy with secukinumab should be considered in patients with refractory BS with a mucosal and articular phenotype.

being definite evidence of its effectiveness on oral ulcers, colchicine is usually the first-line treatment. ${ }^{5}$ Second-line immunosuppressive treatments include azathioprine, thalidomide, interferon- $\alpha$ and tumour necrosis factor (TNF- $\alpha)^{6}{ }^{6}$ The phosphodiesterase- 4 inhibitor apremilast has been recently approved by the Food and Drug Administration for treatment of oral ulcers, ${ }^{7-10}$ while the interleukin (IL)-1 inhibitors anakinra and canakinumab and the anti-IL$12 / 23$ ustekinumab recently emerged as promising options for refractory oral ulcers in BS. ${ }^{11-13}$

Articular involvement is common among patients with BS, with a prevalence of 11\%-93\% depending on the geographical region. ${ }^{14}$ Joint involvement is typically a peripheral, non-deforming, non-erosive, asymmetric mono-oligoarthritis of the large and small joints. ${ }^{15}$ Moreover, $11.6 \%$ of patients with BS experience inflammatory low back pain. ${ }^{14}$ Colchicine is the first-line treatment for the articular 
manifestations of BS, while azathioprine and TNF inhibitor (TNFi) should be considered for refractory patients. ${ }^{6}$ The characteristics of peripheral articular involvement in BS closely resemble those of spondyloarthritis (SpA). Indeed, BS and SpA share a common immunopathogenic background, with major histocompatibility complex class I (MHC-I) molecules and the IL-17 axis as crucial components. ${ }^{16-19}$ A recent pilot study from our centre suggested the efficacy of the anti-IL-17 agent secukinumab in controlling refractory mucosal and axial articular manifestations in a small cohort of patients with BS, especially at a dose of $300 \mathrm{mg} / \mathrm{month} .{ }^{20}$ Despite not being the primary objective of the study, beneficial effects were also observed in peripheral arthritis.

Intriguingly, oral and genital ulcerations and peripheral arthritis are the dominant clinical manifestations of the 'mucosal and articular' phenotype of BS. At the same time, evidence of an increased prevalence of peripheral SpA-like features such as enthesopathy has also been reported in this subset of patients, while axial involvement is inconstant. ${ }^{21}$ The unique attributes of the mucosal and articular phenotype thus strongly hint at a potential utility for anti-IL-17 drugs.

Given the pathogenic and therapeutic background, this multicentre retrospective study primarily aims to investigate the effectiveness and safety profile of secukinumab in patients with BS with a mucosal and articular phenotype refractory to other immunosuppressive treatments. In addition, the study investigates the effects of secukinumab on other disease manifestations, on overall disease activity, and on steroid-sparing and diseasemodifying antirheumatic drug (DMARD)-sparing effects.

\section{METHODS}

\section{Study design and setting}

A multicentre retrospective observational study was performed on a cohort of patients with BS with active mucosal and articular phenotype, treated with secukinumab between November 2016 and November 2019, in the referral centres involved in this study (Firenze, Pisa and Bari, Italy; Adelaide, Australia). All patients signed a written informed consent.

\section{Study population and treatment}

All patients met the International Criteria for Behçet's Disease ${ }^{22}$ and failed or did not tolerate colchicine, a second-line DMARD, and at least one TNFi. Two patients from our preliminary report were included. Comprehensive baseline clinical characteristics are available in online supplementary table 1 . Previous treatments and reasons for starting secukinumab therapy are available in online supplementary table 2 .

All patients had to have at least two episodes of oral aphthosis in the 28 days before secukinumab commencement and a Disease Activity Score (DAS28) >2.6 at the start of treatment. The minimum follow-up time required was set at 6 months. Data were collected up to 24 months, as less than half of patients had a follow-up longer than 2 years.

In patients with polyarticular involvement (ie, $\geq 5$ joints involved), secukinumab was started at a dose of $300 \mathrm{mg} / \mathrm{month}$, while all other patients received $150 \mathrm{mg} / \mathrm{month}$.

Concomitant treatment with corticosteroids, colchicine and DMARDs was continued when necessary, according to clinical practice. No patient was on TNFi at the time of secukinumab commencement.

During follow-up, the secukinumab dose was increased from 150 to $300 \mathrm{mg}$ per month in patients with poor disease control.
In patients experiencing an end-of-dose effect, the frequency of drug injections was increased.

\section{Outcome assessment}

According to clinical practice, patients were evaluated at 3 months (T3) and 6 months (T6) after starting treatment, and then every 6 months (T12, T18, T24).

This study primarily aimed to evaluate the effectiveness of secukinumab in controlling the mucosal and articular BS phenotype. Mucosal involvement was assessed by considering the number of new oral ulcers in the 28 days preceding secukinumab commencement and each follow-up visit. Complete mucosal control was defined as no oral ulcers in the 28 days before the considered evaluation. Peripheral articular involvement was assessed by the DAS28. Complete articular control was defined as DAS28 $\leq 2.6$.

'Complete response' to treatment was considered as the complete control of both mucosal and peripheral articular manifestations (ie, no oral ulcers in the previous 28 days and DAS28 $\leq 2.6$ ). 'Partial response' was defined as a reduction of $50 \%$ or more in the number of oral ulcers in the 28 days before visit and $2.6<$ DAS $28 \leq 3.2$. Patients not meeting the criteria for complete or partial response were classified as non-responders. 'Relapse' was defined as the change from complete to partial or no response, or from partial response to no response. 'Sustained clinical remission' was defined as at least 6 months of uninterrupted response (either complete or partial).

At each visit active BS manifestations (ie, oral and genital ulcers, skin, ocular, vascular, neurological and intestinal symptoms) were assessed, based on clinical evaluation. Axial symptoms were assessed by the Bath Ankylosing Spondylitis Disease Activity Index (BASDAI). The Behçet's Disease Current Activity Form (BDCAF) score was considered to assess the overall BS activity.

To assess the steroid-sparing effect of secukinumab, the proportion of patients receiving corticosteroids and the daily dose of prednisone equivalents were recorded at each visit. In addition, the DMARD-sparing effect of secukinumab was evaluated by considering the proportion of patients receiving cotreatment at each visit. Any change in secukinumab monthly dosage and/or in the frequency of drug administration was recorded.

All adverse events experienced during secukinumab treatment were reported.

\section{Statistical analysis}

Data are presented as median value and IQR and as mean value and SD for continuous variables, and as absolute number and percentage for qualitative variables. Continuous endpoints measured at 3, 6, 12, 18 and 24 months of follow-up were compared with the baseline value using the Wilcoxon signedrank test, whereas qualitative variables were compared using the McNemar's test. The rates of complete or partial response at a defined timepoint were compared in patients treated with secukinumab $150 \mathrm{mg} / \mathrm{month}$ vs $300 \mathrm{mg} / \mathrm{month}$, using the Fisher's exact test. Cox regression models were fitted to derive KaplanMeier curves for the time to achievement of complete mucosal and articular responses. A p value $<0.05$ was considered significant. Statistical analyses were performed using the Stata V.14 software. 
Table 1 Baseline demographic and clinical characteristics of the patients included in this study

\begin{tabular}{ll}
\hline & $\mathbf{n}(\%$ out of 15) \\
\hline Demographic features & \\
\hline Sex (female) & $13(86.7)$ \\
\hline Age at onset, median (IQR) & $40.5(30.6-49.3)$ \\
\hline Age at diagnosis, median (IQR) & $44.5(36.5-55.8)$ \\
\hline Age at secukinumab initiation, median (IQR) & $51.4(45.9-61.7)$ \\
\hline HLA-B51 positivity & $12(80.0)$ \\
\hline Active manifestations at secukinumab initiation & \\
\hline Oral aphthosis & $15(100)$ \\
\hline Peripheral articular involvement & $15(100)$ \\
\hline Axial articular involvement* & $9(60.0)$ \\
\hline Intestinal symptoms & $9(60.0)$ \\
\hline Genital aphthosis & $5(33.3)$ \\
\hline Skin involvement & $4(28.6)$ \\
\hline Neurological involvement & $1(6.7)$ \\
\hline Ocular involvement† & $1(6.7)$ \\
\hline Vascular involvement & 0 \\
\hline Ongoing treatment at secukinumab initiation & \\
\hline Corticosteroids & $9(60.0)$ \\
\hline Colchicine & $6(40.0)$ \\
\hline Methotrexate & $4(26.7)$ \\
\hline Azathioprine & $3(20.0)$ \\
\hline tone pandined as 'chronic symptoms of inflammatory low back pain persisting for more \\
\hline
\end{tabular}

\section{RESULTS}

\section{Patients' characteristics}

During the study period a total of 19 patients with BS in therapy with secukinumab were enrolled. Two patients were excluded as their follow-up was shorter than 6 months. In one case secukinumab was withdrawn early due to mood disorders. One more patient was excluded due to lack of peripheral joint involvement at the time of secukinumab commencement. A final number of 15 patients with active 'mucosal and articular' BS phenotype under treatment with secukinumab were included in this study.

The main demographics and clinical characteristics are summarised in table 1 .

Most patients in our cohort were female $(n=13,86.7 \%)$, with a median age at treatment initiation of 51.4 years (IQR 45.9-61.7). All patients had active oral aphthosis and peripheral arthritis. Additional active BS manifestations were axial involvement $(n=9)$, intestinal symptoms $(n=9)$, genital aphthosis $(n=5)$, and skin $(n=4)$, neurological $(n=1)$ and ocular $(n=1)$ involvement. No patient had active vascular manifestations.

All patients had been previously treated with colchicine, traditional DMARDs and at least one TNFi. Previous DMARDs included azathioprine $(n=9)$, methotrexate (MTX) $(n=8)$, ciclosporin $(n=6)$ and thalidomide $(n=1)$. At the time secukinumab was started, most patients were taking corticosteroids $(n=9$, $60.0 \%)$ and/or colchicine $(n=6,40.0 \%)$. MTX, azathioprine and hydroxychloroquine were taken concurrently in four, three and one patient, respectively.

\section{Secukinumab effectiveness}

Mucosal and articular phenotype

Within 3 months (T3), 10 (66.7\%) patients had achieved a response (complete or partial) in terms of control of the mucosal and articular BS phenotype, as defined in the Methods section (table 2). This proportion sharply increased at T6 (86.7\%), T12 (76.9\%), T18 (90.0\%) and T24 (100.0\%).

Out of 13 patients with a follow-up longer than 6 months, 11 $(84.6 \%)$ achieved a sustained clinical remission, $6(54.5 \%)$ of whom without any concomitant treatment with corticosteroids and $5(45.5 \%)$ treated with prednisone $5 \mathrm{mg}$ daily. Moreover, $9(90.0 \%)$ out of 10 patients with a follow-up longer than a year showed 12 months of uninterrupted response. Considering mucosal and articular manifestations separately, the median number of oral ulcers per 28 days greatly decreased starting

Table 2 Effectiveness of secukinumab in the mucosal and articular phenotype

\begin{tabular}{|c|c|c|c|c|c|c|c|c|c|c|c|}
\hline & Baseline & Month 3 & P value* & Month 6 & P value* & Month 12 & $P$ value* & Month 18 & $P$ value* & Month 24 & P value* \\
\hline $\begin{array}{l}\text { Number of } \\
\text { observations }\end{array}$ & 15 & 15 & & 15 & & 13 & & 10 & & 8 & \\
\hline $\begin{array}{l}\text { Overall } \\
\text { response }\end{array}$ & - & $10(66.7)$ & & $13(86.7)$ & & $10(76.9)$ & & $9(90.0)$ & & $8(100.0)$ & \\
\hline $\begin{array}{l}\text { Complete } \\
\text { response }\end{array}$ & - & $4(26.7)$ & & $7(46.7)$ & & 7 (53.9) & & $5(50.0)$ & & 7 (87.5) & \\
\hline $\begin{array}{l}\text { Partial } \\
\text { response }\end{array}$ & - & $6(40.0)$ & & $6(40.0)$ & & $3(23.1)$ & & $4(40.0)$ & & $1(12.5)$ & \\
\hline No response & - & $5(33.3)$ & & $2(13.3)$ & & $3(23.1)$ & & $1(10.0)$ & & 0 & \\
\hline \multicolumn{12}{|c|}{ Control of the mucosal and articular involvements } \\
\hline $\begin{array}{l}\text { Number of } \\
\text { oral ulcers in } \\
\text { the last } 28 \\
\text { days } \\
\text { Median (IQR) }\end{array}$ & $2(2-3)$ & $1(0-1)$ & $0.006 t$ & $0(0-1)$ & $<0.001 \dagger$ & $0(0-0)$ & $0.002 \dagger$ & $0.5(0-1)$ & $0.005 t$ & $0(0-0)$ & $0.012 \dagger$ \\
\hline Mean \pm SD & $2.4 \pm 1.4$ & $0.9 \pm 1.2$ & & $0.3 \pm 0.6$ & & $0.4 \pm 0.9$ & & $0.5 \pm 0.5$ & & $0.1 \pm 0.4$ & \\
\hline $\begin{array}{l}\text { DAS28 } \\
\text { Median (IQR) }\end{array}$ & $3.9(2.9-4.2)$ & $2.6(2.2-3.1)$ & $0.005 t$ & $2.5(2.0-2.9)$ & $<0.001 \dagger$ & $2.6(1.9-3.4)$ & $0.011 \dagger$ & $2.2(2-2.3)$ & $0.005 \dagger$ & $2.1(1.6-2.4)$ & $0.012 \dagger$ \\
\hline Mean \pm SD & $3.8 \pm 0.8$ & $2.9 \pm 0.9$ & & $2.4 \pm 0.6$ & & $2.6 \pm 0.8$ & & $2.2 \pm 0.7$ & & $2.0 \pm 0.6$ & \\
\hline Relapse & - & - & & $1(6.7)$ & & $3(25.1)$ & & $4(40.0)$ & & $0(0)$ & \\
\hline
\end{tabular}

${ }^{*}$ Wilcoxon signed-rank test as compared with the baseline value.

†Statistically significant at $\mathrm{p}<0.05$.

DAS28, Disease Activity Score 


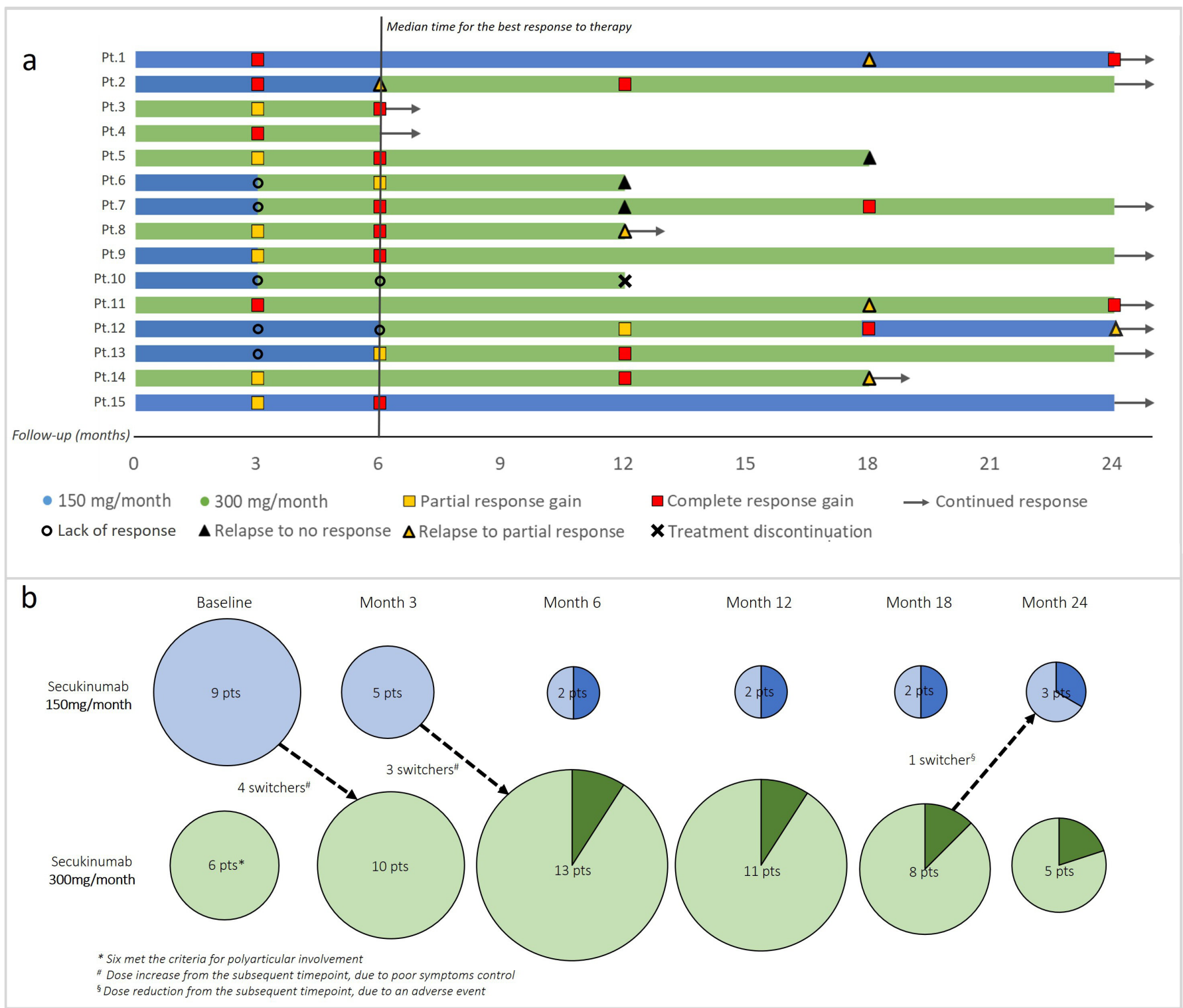

Figure 1 (A) Swimmer plot of patients' response to treatment during follow-up The coloured lanes represent the extent of available follow-up for each patient. Blue-coloured lanes indicate ongoing treatment with secukinumab $150 \mathrm{mg} / \mathrm{month}$, while green-coloured lanes indicate treatment with secukinumab $300 \mathrm{mg} / \mathrm{month}$. Treatment events are marked with squares and triangles, representing response achievement and relapse, respectively. Cases of treatment discontinuation are marked by a black cross. A lack of response at month 6 is indicated by a black circle. The median time to achievement of each patient's best response to therapy is shown with a vertical black line. (B) Variations in the monthly dose of secukinumab during follow-up and occurrence of end-of-dose effects. Dashed lines represent patients switching from secukinumab $150 \mathrm{mg}$ to $300 \mathrm{mg}$ per month. The dark blue and dark green areas within circles represent the proportion of patients (pts) experiencing an end-of-dose effect, that is, reducing the frequency of drug administration from every 28 days to every 17 or 21 days.

from T3 $(p=0.006)$ and the reduction retained high statistical significance at T6 $(\mathrm{p}<0.001)$, T12 $(\mathrm{p}=0.002)$, T18 $(\mathrm{p}=0.005)$ and T24 $(p=0.013)$. Similarly, DAS28 dropped significantly at T3 $(p=0.005)$, T6 $(p<0.001)$, T12 $(p=0.011)$, T18 $(p=0.005)$ and T24 $(\mathrm{p}=0.012)$.

Overall, nine patients had a relapse. Two relapses occurred in patients treated with secukinumab $150 \mathrm{mg} /$ month: in one case increasing the dosage to $300 \mathrm{mg} / \mathrm{month}$ was necessary in order to reachieve a complete response, while no additional data were available for the other as the relapse occurred at the last available follow-up. The other seven relapses occurred in patients on secukinumab $300 \mathrm{mg} / \mathrm{month}$ : two patients spontaneously reachieved remission within the subsequent follow-up, another patient reachieved complete response after introducing cotherapy with
MTX, while no follow-up data were available for the remaining four patients (figure 1).

The time to achieve mucosal and articular responses is shown in online supplementary figure 1 .

Other Behçet's manifestations and overall activity

The effect of secukinumab on other BS manifestations is reported in table 3. Secukinumab effectively controlled the axial articular involvement. Namely, BASDAI significantly decreased at T3 $(\mathrm{p}=0.009), \mathrm{T} 6(\mathrm{p}=0.012), \mathrm{T} 12(\mathrm{p}=0.017)$ and T18 $(\mathrm{p}=0.043)$.

Notably, secukinumab accounted for a consistent and rapid control of intestinal BS symptoms such as abdominal pain and distension and diarrhoea. The proportion of patients with active 
Table 3 Effectiveness of secukinumab in other disease manifestations

\begin{tabular}{|c|c|c|c|c|c|c|c|c|c|c|c|}
\hline & Baseline & Month 3 & P value* & Month 6 & P value* & Month 12 & P value* & Month 18 & P value* & Month 24 & P value* \\
\hline Number of observations & 15 & 15 & & 15 & & 13 & & 10 & & 8 & \\
\hline \multicolumn{12}{|l|}{ Disease manifestations } \\
\hline $\begin{array}{l}\text { BASDAI (axial articular involvement) } \\
\text { Median (IQR) }\end{array}$ & $4.7(0-7)$ & $3(0-5)$ & $0.009 \ddagger$ & $1.6(0-4.5)$ & $0.012 \ddagger$ & $2.5(0-4)$ & $0.017 \ddagger$ & $2.9(0-3.4)$ & $0.043 \ddagger$ & $1.5(0-3.7)$ & 0.079 \\
\hline Mean \pm SD $\dagger$ & $3.8 \pm 3.4$ & $2.7 \pm 2.8$ & & $1.9 \pm 2.1$ & & $2.5 \pm 2.4$ & & $2.4 \pm 1.9$ & & $1.8 \pm 2.0$ & \\
\hline Intestinal symptoms & $9(60.0)$ & $2(13.3)$ & $0.008 \ddagger$ & $0(0)$ & $0.003 \ddagger$ & $1(7.7)$ & 0.034 & $0(0)$ & $0.025 \ddagger$ & $0(0)$ & $0.046 \ddagger$ \\
\hline Genital aphthosis & $5(33.3)$ & $1(6.7)$ & $0.046 \ddagger$ & $0(0)$ & $0.025 \ddagger$ & $0(0)$ & $0.025 \ddagger$ & $1(10.0)$ & 0.083 & $0(0)$ & 0.083 \\
\hline Skin involvement & $4(28.6)$ & $2(13.3)$ & 0.317 & $1(6.7)$ & 0.083 & $3(23.1)$ & 0.564 & $0(0)$ & 0.083 & $1(12.5)$ & 0.317 \\
\hline Neurological involvement & $1(6.7)$ & $2(13.3)$ & 0.564 & $3(20.0)$ & 0.157 & $2(15.4)$ & 0.564 & $0(0)$ & 1.000 & $0(0)$ & 1.000 \\
\hline Ocular involvement & $1(6.7)$ & $1(6.7)$ & 1.000 & $0(0)$ & 0.317 & $0(0)$ & 0.317 & $0(0)$ & 0.317 & $0(0)$ & 1.000 \\
\hline Vascular involvement & $0(0)$ & $0(0)$ & - & $0(0)$ & - & $0(0)$ & - & $0(0)$ & - & $0(0)$ & - \\
\hline \multicolumn{12}{|l|}{ Disease activity } \\
\hline $\begin{array}{l}\text { BDCAF } \\
\text { Median (IQR) }\end{array}$ & $8(7-9)$ & $5(3-7)$ & $<0.001 \ddagger$ & $3(3-5)$ & $<0.001 \ddagger$ & $3(1-3)$ & $0.002 \ddagger$ & $2(0-3)$ & $0.005 \ddagger$ & $1.5(0-3)$ & $0.011 \ddagger$ \\
\hline Mean \pm SD $†$ & $7.9 \pm 1.4$ & $4.5 \pm 2.3$ & & $3.5 \pm 2.1$ & & $3.0 \pm 2.5$ & & $2.2 \pm 2.4$ & & $1.5 \pm 1.6$ & \\
\hline
\end{tabular}

${ }^{*}$ McNemar's test as compared with baseline.

tWilcoxon signed-rank test as compared with the baseline value.

$\ddagger$ Statistically significant at $p<0.05$.

BASDAI, Bath Ankylosing Spondylitis Disease Activity Index; BDCAF, Behçet's Disease Current Activity Form.

intestinal manifestations dropped significantly and steadily at $\mathrm{T} 3$ $(\mathrm{p}=0.008), \mathrm{T} 6(\mathrm{p}=0.003), \mathrm{T} 12(\mathrm{p}=0.034), \mathrm{T} 18(\mathrm{p}=0.025)$ and $\mathrm{T} 24(\mathrm{p}=0.046)$. Of particular note, data on faecal calprotectin (FC) levels at baseline and following secukinumab treatment were available for four patients with active gastrointestinal manifestations. In two patients, FC normalised, dropping from 127 $\mu \mathrm{g} / \mathrm{g}$ at T0 to $20 \mu \mathrm{g} / \mathrm{g}$ at T6 and $18 \mu \mathrm{g} / \mathrm{g}$ at T18 in one case, and from $71 \mu \mathrm{g} / \mathrm{g}$ at T0 to $8 \mu \mathrm{g} / \mathrm{g}$ at T6 in the other. In the other two patients, FC decreased from $180 \mu \mathrm{g} / \mathrm{g}$ at T0 to $61 \mu \mathrm{g} / \mathrm{g}$ at T6, and from $178 \mu \mathrm{g} / \mathrm{g}$ at T0 to $64 \mu \mathrm{g} / \mathrm{g}$ at T3, respectively.

Secukinumab was also beneficial in genital ulcers, for which a significant decrease was already evident at T3 $(p=0.046)$ and was confirmed at T6 $(\mathrm{p}=0.025), \mathrm{T} 12(\mathrm{p}=0.025)$ and T18 $(\mathrm{p}=0.083)$.

Positive effects on skin involvement, although not significant, were also observed.

The BDCAF score for the global assessment of disease activity significantly decreased at T3 $(\mathrm{p}<0.001)$, T6 $(\mathrm{p}<0.001)$, T12 $(\mathrm{p}=0.002), \mathrm{T} 18(\mathrm{p}=0.005)$ and T24 $(\mathrm{p}=0.011)($ table 3$)$.

\section{Steroid-sparing and DMARD-sparing effect and secukinumab schedule variations}

Although only a minor proportion of patients completely discontinued corticosteroid treatment, secukinumab allowed significant reduction in the daily dose of prednisone equivalents (table 4). Indeed, the median dose of prednisone decreased at each timepoint, with statistical significance at T3 $(p=0.009)$ and T6 $(\mathrm{p}=0.006)$.

At baseline, four patients were receiving MTX for arthritis control (table 4). Within 3 months, all had discontinued MTX and remained MTX-free during the first year of follow-up. At T18, a fourth patient needed to start MTX due to worsening arthralgias (figure 1).

Throughout follow-up, all but two of the nine patients who were initially on secukinumab $150 \mathrm{mg} / \mathrm{month}$ had to switch to a higher dosage due to poor symptoms control. In contrast, only one patient taking $300 \mathrm{mg} /$ month switched to a lower dosage due to a mild adverse event (figure 1). There was only one case of secukinumab discontinuation for persistent lack of response at month 12 .
According to the summary of product characteristics, the drug was initially administered subcutaneously every week for 5 weeks and then every 28 days. However, during follow-up, four patients developed symptoms prior to their planned administration of secukinumab (ie, end-of-dose effect) and needed to increase the frequency of administration (two patients received secukinumab every 21 days and two every 17 days) to reachieve the control of mucosal and articular manifestations.

\section{Safety}

Two patients experienced Candida infection after 6 months of treatment with secukinumab $300 \mathrm{mg} / \mathrm{month}$ (ie, glossitis, oral and vaginal candidiasis). Gingivitis occurred in one patient after 18 months, but symptoms reverted after switching to a lower dosage. Finally, one patient reported vertigo and mild mood disorders. No dose-related or serious adverse event was reported in all other patients.

\section{DISCUSSION}

The extreme variability of clinical manifestations in BS has made the definition of clinical phenotypes an essential asset for our understanding of the disease. Indeed, the predominant phenotypes have already been defined and are thought to be governed by different disease mechanisms requiring diversified treatment modalities. ${ }^{23}$ Here we report the results of a retrospective study conducted on a series of 15 patients with the mucosal and articular phenotype of BS and treated with secukinumab. The observed effectiveness of secukinumab in this phenotype has a strong pathophysiological basis. Indeed, studies have revealed a role of IL-17 in the pathogenesis of BS, as well as in that of recurrent oral ulcers. ${ }^{17}{ }^{24}$ Intriguingly, tackling the IL-17 axis with anti-IL-12/23 ustekinumab recently proved effective for the treatment of refractory oral ulcers in BS while also improving joint involvement. ${ }^{13}$

In our study, we found evidence supporting the use of secukinumab as an effective and safe therapy for the long-term treatment of active mucosal and articular manifestations of BS.

Despite our cohort of patients including refractory cases of BS with persistently active mucosal and articular disease, we 


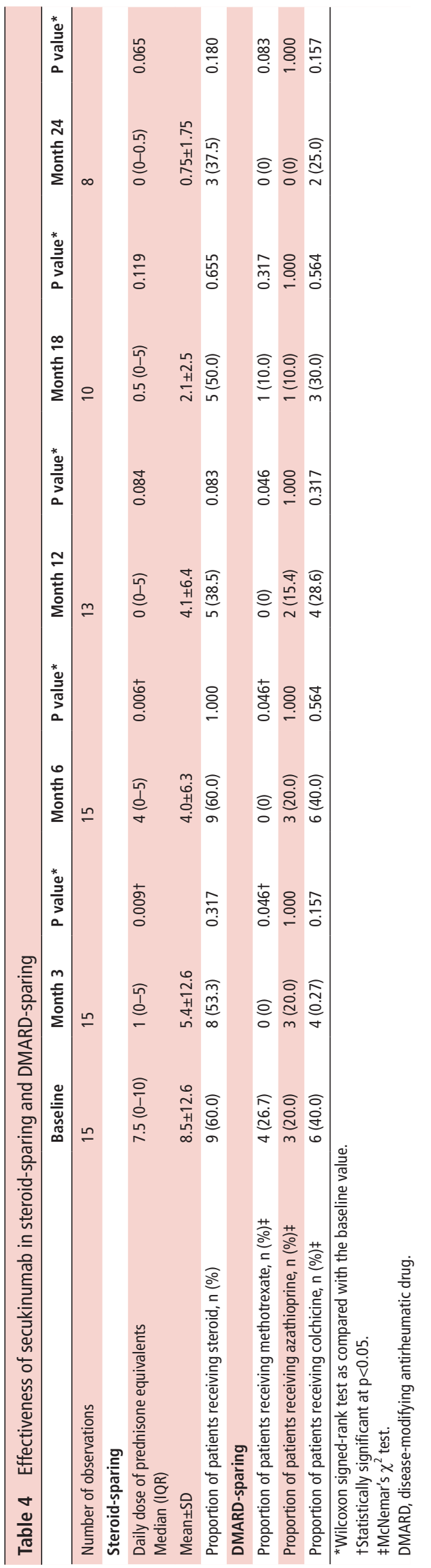

observed a rapid and significant reduction in the number of oral ulcers, with the majority of patients reportedly ulcer-free in the 28 days prior to visit. This was paralleled by a significant improvement in peripheral arthritis. The proportion of complete responders steadily increased throughout follow-up, and the majority of patients achieved a sustained clinical remission. As already suggested in our preliminary study, the $300 \mathrm{mg} / \mathrm{month}$ dosage seemed superior to $150 \mathrm{mg} / \mathrm{month}$ in controlling both aspects of the phenotype.

As a downside, an increased number of mucosal and articular relapses were observed after the first year of therapy. However, no other systemic manifestations of BS occurred. In all the cases with an available follow-up, a complete response was reachieved either spontaneously or by increasing the secukinumab dosage or by adding cotherapy with MTX.

Nevertheless, our data also suggest that secukinumab can be safely and beneficially used for other aspects of the disease, such as genital aphthosis, axial arthritis and intestinal symptoms. The efficacy on genital aphthosis is not surprising as it probably shares the same pathogenesis with oral ulcers. Positive results for axial arthritis were anticipated, since secukinumab is currently approved for the treatment of psoriatic arthritis (PsA) and ankylosing spondylitis (AS).

It has previously been suggested that secukinumab may increase the risk of inflammatory bowel disease (IBD) in patients with axial SpA. ${ }^{25}$ However, a retrospective analysis of 7355 patients with psoriasis, PsA and AS has shown that exposure-adjusted incidence rates for IBD do not increase with secukinumab treatment. ${ }^{26}$ Quite interestingly, we observed an improvement in intestinal symptoms in our patients, accompanied by a corresponding decrease in FC values.

Long-term therapy with secukinumab also proved to be safe in patients with a history of ophthalmological involvement (including one with active anterior uveitis at the time of secukinumab commencement), as no ocular exacerbations were reported throughout follow-up. While subcutaneous secukinumab has proven ineffective in active BS non-infectious uveitis, ${ }^{27}$ a recent trial showed that the intravenous route was effective and well tolerated, suggesting that changing the route of administration could be necessary in order to deliver secukinumab in therapeutic concentrations in the eye in case of active disease. $^{28}$

Overall, BDCAF-assessed disease control improved significantly in all patients and values remained stably low.

In addition, secukinumab treatment showed steroid-sparing and DMARD-sparing effects, allowing for prednisone tapering, MTX discontinuation in all patients and colchicine discontinuation in half the cases.

Secukinumab was generally well tolerated at both dosages, without significant dose-related or serious adverse events. Mood disorders were reported in one case but did not lead to the suspension of treatment. Interestingly, there is conflicting evidence about a potential role of IL-17 in depressive states..$^{29-31}$

The main limitations of this study are its retrospective nature and the relatively small number of observed patients. Moreover, a survivorship bias may emerge as a consequence of the minimum follow-up time of 6 months and could result in a slight underestimation of non-responders.

However, the adopted response criteria are quite stringent in terms of control of articular symptoms and ulcer-free time (ie, 28 days), thus conferring high clinical significance to the presented results in spite of sample size.

In conclusion, our study suggests that the anti-IL-17 agent secukinumab is a safe and effective therapy for patients with BS 
with a mucosal and articular phenotype even when refractory to previous treatments, as it acts on both manifestations concomitantly. Secukinumab $300 \mathrm{mg} / \mathrm{month}$ showed superior effectiveness in inducing complete remission in all patients, including those who did not show satisfactory response to the $150 \mathrm{mg} /$ month dosage.

These data are in line with the idea that specific phenotypes of BS may benefit from tailored therapeutic approaches. ${ }^{23}$ Moreover, data on the effects of secukinumab in single disease manifestations are also encouraging. In the future, more studies will be needed in order to better characterise the therapeutic effects of secukinumab in BS and to diversify the pharmacological approach to this complex multifaceted condition.

\section{Patient and public involvement}

This research was done without patient involvement. Patients were not invited to comment on the study design and were not consulted to develop patient relevant outcomes or interpret the results. Patients were not invited to contribute to the writing or editing of this document for readability or accuracy.

Contributors Study conception and design: $F, A B, G D S, G E$. Acquisition of data: $R T, G L, E S, M L U, P A J R$. Analysis and interpretation of data: FF, AB, GDS, GE, DP. All the authors approved the final version of the manuscript.

Funding The authors have not declared a specific grant for this research from any funding agency in the public, commercial or not-for-profit sectors.

Competing interests None declared.

Patient and public involvement Patients and/or the public were not involved in the design, or conduct, or reporting, or dissemination plans of this research.

Patient consent for publication Not required.

Ethics approval The study is approved by the Ethics Committee of Area Vasta Centro (competent for the Azienda Ospedaliero Universitaria Careggi), and was conducted in accordance with the Declaration of Helsinki.

Provenance and peer review Not commissioned; externally peer reviewed.

Data availability statement All data relevant to the study are included in the article or uploaded as supplementary information.

\section{ORCID iDs}

Rosaria Talarico http://orcid.org/0000-0003-4268-9611

Giuseppe Lopalco http://orcid.org/0000-0003-4524-9566

Gerardo Di Scala http://orcid.org/0000-0002-2245-5589

\section{REFERENCES}

1 Bettiol A, Prisco D, Emmi G. Behçet: the syndrome. Accepted in Rheumatology 2019;00:1-7.

2 Seyahi E. Phenotypes in Behçet's syndrome. Intern Emerg Med 2019;14:677-89.

3 Emmi G, Silvestri E, Squatrito D, et al. Behçet's syndrome pathophysiology and potential therapeutic targets. Intern Emerg Med 2014;9:257-65.

4 Fabiani C, Vitale A, Orlando I, et al. Quality of life impairment in Behçet's disease and relationship with disease activity: a prospective study. Intern Emerg Med 2017:12:947-55.

5 Esatoglu SN, Hatemi G. Update on the treatment of Behçet's syndrome. Intern Emerg Med 2019:14:661-75.

6 Hatemi G, Christensen R, Bang D, et al. 2018 update of the EULAR recommendations for the management of Behçet's syndrome. Ann Rheum Dis 2018;77:808-18.

7 Search orphan drug designations and approvals. Available: https://www.accessdata. fda.gov/scripts/opdlisting/oopd/detailedlndex.cfm?cfgridkey=384812 [Accessed 20 Dec 2019].
8 Lopalco $G$, Venerito V, Leccese $P$, et al. Real-world effectiveness of apremilast in multirefractory mucosal involvement of Behçet's disease. Ann Rheum Dis 2019;78:1736-7.

9 Hatemi G, Melikoglu M, Tunc R, et al. Apremilast for Behçet's syndrome--a phase 2, placebo-controlled study. N Engl J Med 2015;372:1510-8.

10 Hatemi G, Mahr A, Ishigatsubo Y, et al. Trial of apremilast for oral ulcers in Behçet's syndrome. N Eng/ J Med 2019;381:1918-28.

11 Bettiol A, Silvestri E, Di Scala G, et al. The right place of interleukin-1 inhibitors in the treatment of Behçet's syndrome: a systematic review. Rheumatol Int 2019:39:971-90.

12 Emmi G, Talarico R, Lopalco G, et al. Efficacy and safety profile of anti-interleukin-1 treatment in Behçet's disease: a multicenter retrospective study. Clin Rheumatol 2016;35:1281-6.

13 Mirouse A, Barete S, Desbois A-C, et al. Long-term outcome of ustekinumab therapy for Behçet's disease. Arthritis Rheumatol 2019;71:1727-32.

14 Fatemi A, Shahram F, Akhlaghi M, et al. Prospective study of articular manifestations in Behcet's disease: five-year report. Int J Rheum Dis 2017:20:97-102.

15 Park JH. Clinical analysis of Behçet disease: arthritic manifestations in Behçet disease may present as seronegative rheumatoid arthritis or palindromic rheumatism. Korean J Intern Med 1999;14:66-72.

16 Na SY, Park M-J, Park S, et al. Up-regulation of Th17 and related cytokines in Behçet's disease corresponding to disease activity. Clin Exp Rheumatol 2013:31:32-40.

17 Nanke Y, Yago T, Kotake S. The Role of Th17 Cells in the Pathogenesis of Behcet's Disease. J Clin Med 2017:6:74

18 Emmi G, Prisco D. Behçet's syndrome: focus on pathogenetic background, clinical phenotypes and specific treatments. Intern Emerg Med 2019;14:639-43.

19 Giza M, Koftori D, Chen L, et al. Is Behçet's disease a 'class 1-opathy'? The role of HLA-B*51 in the pathogenesis of Behçet's disease. Clin Exp Immunol 2018:191:11-18.

20 Di Scala G, Bettiol A, Cojan RD, et al. Efficacy of the anti-IL 17 secukinumab in refractory Behçet's syndrome: a preliminary study. J Autoimmun 2019;97:108-13.

21 Hatemi G, Fresko I, Tascilar K, et al. Increased enthesopathy among Behçet's syndrome patients with acne and arthritis: an ultrasonography study. Arthritis Rheum 2008:58:1539-45.

22 International Team for the Revision of the International Criteria for Behçet's Disease (ITR-ICBD). The International Criteria for Behçet's Disease (ICBD): a collaborative study of 27 countries on the sensitivity and specificity of the new criteria. J Eur Acad Dermatol Venereol 2014;28:338-47.

23 Bettiol A, Hatemi G, Vannozzi L, et al. Treating the different phenotypes of Behçet's syndrome. Front Immunol 2019:10.

24 Al-Samadi A, Kouri V-P, Salem A, et al. II-17C and its receptor IL-17RA/IL-17RE identify human oral epithelial cell as an inflammatory cell in recurrent aphthous ulcer. J Oral Pathol Med 2014;43:117-24.

25 Fobelo Lozano MJ, Serrano Giménez R, Castro Fernández M. Emergence of inflammatory bowel disease during treatment with Secukinumab. J Crohns Colitis 2018:12:1131-1133.

26 Schreiber S, Colombel J-F, Feagan BG, et al. Incidence rates of inflammatory bowe disease in patients with psoriasis, psoriatic arthritis and ankylosing spondylitis treated with secukinumab: a retrospective analysis of pooled data from 21 clinical trials. Ann Rheum Dis 2019:78:473-9.

27 Dick AD, Tugal-Tutkun I, Foster S, et al. Secukinumab in the treatment of noninfectious uveitis: results of three randomized, controlled clinical trials. Ophthalmology 2013:120:777-87.

28 Letko E, Yeh S, Foster CS, et al. Efficacy and safety of intravenous secukinumab in noninfectious uveitis requiring steroid-sparing immunosuppressive therapy. Ophthalmology 2015;122:939-48.

29 Nadeem A, Ahmad SF, Al-Harbi NO, et al. Il-17A causes depression-like symptoms via NFKB and p38MAPK signaling pathways in mice: implications for psoriasis associated depression. Cytokine 2017:97:14-24.

30 Li Y-C, Chou Y-C, Chen H-C, et al. Interleukin-6 and interleukin- 17 are related to depression in patients with rheumatoid arthritis. Int J Rheum Dis 2019:22:980-5.

31 Jha MK, Minhajuddin A, Gadad BS, et al. Interleukin 17 selectively predicts better outcomes with bupropion-SSRI combination: novel T cell biomarker for antidepressant medication selection. Brain Behav Immun 2017:66:103-10. 